NASA-CR-202500

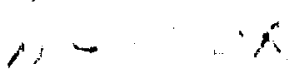

Geological Society of America

Special Paper 293

1994

\title{
Coincidence in time of the Imbrium basin impact and Apollo 15 KREEP volcanic flows: The case for impact-induced melting
}

Graham Ryder

Lunar and Planetary Institute, 3600 Bay Area Boulevard, Houston, Texas 77058

\begin{abstract}
On the Earth there is no firm evidence that impacts can induce volcanic activity. However, the Moon does provide a very likely example of volcanism induced by an immense impact: the Imbrium basin-forming event was immediately succeeded by a crustal partial melting event that released basalt flows characterized by $K$, rare-earth elements (REE), $P$, and other trace elements (KREEP) over a wide area creating the Apennine Bench Formation. Impact total melting is inconsistent with the chemistry and petrography of these Apollo 15 KREEP basalts, which are quite unlike the impact melts recognized at Taurus-Littrow as the products of the Serenitatis impact. The Imbrium impact and the KREEP volcanic events are indistinguishable in radiometric age, and thus the volcanism occurred less than about $20 \mathrm{Ma}$ later than the impact (less than about $0.5 \%$ of lunar history). The sample record indicates that such KREEP volcanism had not occurred in the region prior to that time, and demonstrates that it never occurred again. Such coincidence in time implies a genetic relationship between the two events, and impact-induced partial melting or release appears to be the only feasible process. Nonetheless, the characteristics of the Apollo 15 KREEP basalts suggest large-degree crustal melting that is not easy to reconcile with the inability of lunar pressure release alone to induce partial melting unless the source was already almost at its melting point. The earliest history of the surface of the Earth, at a time of greater internal heat production and basin-forming impacts, could have been greatly influenced by impact-induced melting.
\end{abstract}

\section{INTRODUCTION}

This paper clarifies and extends the argument that KREEP volcanism that produced the Apennine Bench Formation on the Moon is an example of volcanism induced by a large impact, as first suggested although not explored by Spudis (1978). The recognition of such inducement leads to inferences about the initial conditions of the target on the Moon and the pertinent magmatic processes. Impact-induced volcanism has some ramifications, in particular for the earliest history of the Earth, and these are briefly explored.

There is no firm evidence that impacts have induced magmatic activity on the Earth, although such inducement has been proposed for intrusions at both the Sudbury and Vredefort structures, and less forcefully for the initiation of some volcanic flood basalts such as the North Atlantic province. That impact-induced volcanism was responsible for the maria on the Moon was demonstrated to be false by detailed stratigraphic analysis, by imaging of empty basins, and finally by radiometric analysis of lunar samples (summarized by Wilhelms, 1970, 1987). The concept that melt-appearing features in smaller craters such as Tycho were volcanic (the "hybrid" impact-volcanic concept) was replaced by the accepted impact melt hypothesis as understanding of the impact process grew (e.g., Howard and Wilshire, 1975; Wilhelms, 1987). Apart from a lack of observational evidence, there is a difficulty in under-

Ryder, G., 1994, Coincidence in time of the Imbrium basin impact and Apollo 15 KREEP volcanic flows: The case for impact-induced melting, in Dressler, B. O., Grieve, R.A.F., and Sharpton, V. L., eds., Large Meteorite Impacts and Planetary Evolution: Boulder, Colorado, Geological Society of America Special Paper 293. 
standing possible mechanisms of impact-induced partial melting (as distinct from the production of super-heated total melting). The total heat input from an impact is concentrated into a small proportion of the total crater or basin in the central part; much of that heat goes into producing an impact melt, which is a total rather than partial or induced melt. Further, any post-impact pressure-release effect is rather small, especially on the Moon. Thus most modern workers have been led to discount or neglect impact-induced magmatism.

Magmatism requires not only melt production but melt movement. Impact could facilitate the migration of melt already present beneath a target, for example by crust removal, central peak uplift, and conduit formation by fracturing. Either alone or supplemented with melting from heat input and pressure changes, these processes could conceivably produce nearsurface magmatism. Thus demonstration of an example of impact-induced volcanism would be important in establishing the reality of the process and would be a starting point for understanding the state of the crust and mantle around the impact point, the effects of the impact itself, and the possible significance of the process in planetary history. Establishment of the Apollo 15 KREEP volcanic samples as impact-induced or otherwise is of some significance.

\section{THE ARGUMENT FOR IMPACT-INDUCED MELTING FOR THE APENNINE BENCH FORMATION}

The essence of the argument, each to be inspected in more detail, is that

1. The Apennine Bench Formation postdates the Imbrium event.

2. The Apennine Bench Formation is volcanic in origin and not an impact melt or other ejecta sheet.

3. The Apennine Bench Formation is represented by the fragments of KREEP basalt collected at the Apollo 15 landing site.

4. The Apollo 15 KREEP basalts are of volcanic, not impact, origin and have been dated at $3.84 \pm 0.02 \mathrm{Ga}$.

5. The Imbrium event took place at $3.84 \pm 0.02 \mathrm{Ga}$.

6. The particular type of KREEP volcanism represented by the Apennine Bench Formation never occurred in the region again and had probably not occurred there before. Thus

7. The unique KREEP volcanism of the Apennine Bench Formation immediately succeeded the Imbrium event and must have been induced by it.

Each of these links in the argument requires explanation and justification. The first four were discussed by Spudis (1978) and to a lesser extent by Hawke and Head (1978) but more information is now available for points 3,4 and 5 .

\section{Apennine Bench Formation postdates the Imbrium Event}

Hackman (1966) defined materials that formed moderately high albedo plains near the crater Archimedes as the
Apennine Bench Formation, and the name has been extended to other similar plains inside the Imbrium-basin rim that underlie deposits of Imbrian craters and the mare (Page, 1970; Wilhelms, 1970, 1987). The plains of the Apennine Bench Formation (Fig. 1) are located primarily between the second and third rings of the basin. They embay and overlap the terra materials that form the topography of the Imbrium basin and thus must postdate it. They predate the crater Archimedes whose ejecta overlie them, and predate the mare plains, which overlap and embay them and are far less cratered (Fig. 1). Once they may have formed a continuous unit; however, they are now only patchily exposed at the surface. Thus the Apennine Bench Formation is part of the Lower Imbrian Series and is the oldest post-Imbrium unit in the region.

\section{The Apennine Bench Formation is volcanic in origin}

Although the surface morphology of the Apennine Bench Formation has been obscured by subsequent events, both Spudis (1978) and Hawke and Head (1978) showed that there is compelling morphological evidence that the plains were not only emplaced as fluids but as volcanic flows and not as an impact melt sheet. The Orientale basin has no such plains in an analogous position, and the Apennine Bench Formation is relatively smooth and flat compared with the outer corrugated melt facies at Orientale. The Formation does not drape or locally flow off highlands but embays them and is at a fairly constant elevation. No unequivocal volcanic landforms have been identified (Spudis, 1978), but some of the abundant grabens and particularly some surface depressions might be related to volcanic activity if they are not all from Imbrium basin subsidence.

\section{The Apennine Bench Formation is represented by Apollo 15 KREEP basalts fragments}

The chemistry of the Apennine Bench Formation has been inferred from data from orbiting instruments on the Apollo 15 command module and earth-based spectral reflectance techniques (e.g. Adler and Trombka, 1977; Spudis, 1978; Metzger et al., 1979). As shown by Spudis (1978), the chemical data are consistent with the formation being of the composition of a KREEP basalt, that is, an aluminous basalt with elevated levels of incompatible element abundances. In particular, deconvolution of gamma-ray data suggests a Th abundance of about 11 ppm (Metzger et al., 1979). Earthbased reflectance spectra for locations on the Apennine Bench show characteristics consistent with either clinopyroxene or Fe-glass, or both, consistent with the Apollo 15 KREEP basalts, which contain pigeonite-augite and interstitial $\mathrm{Fe}$ glass. Other regional units do not have these spectral characteristics (Spudis et al., 1988).

The Apollo 15 landing site was within $50 \mathrm{~km}$ of exposures of the Apennine Bench Formation (Fig. 1), where it un- 


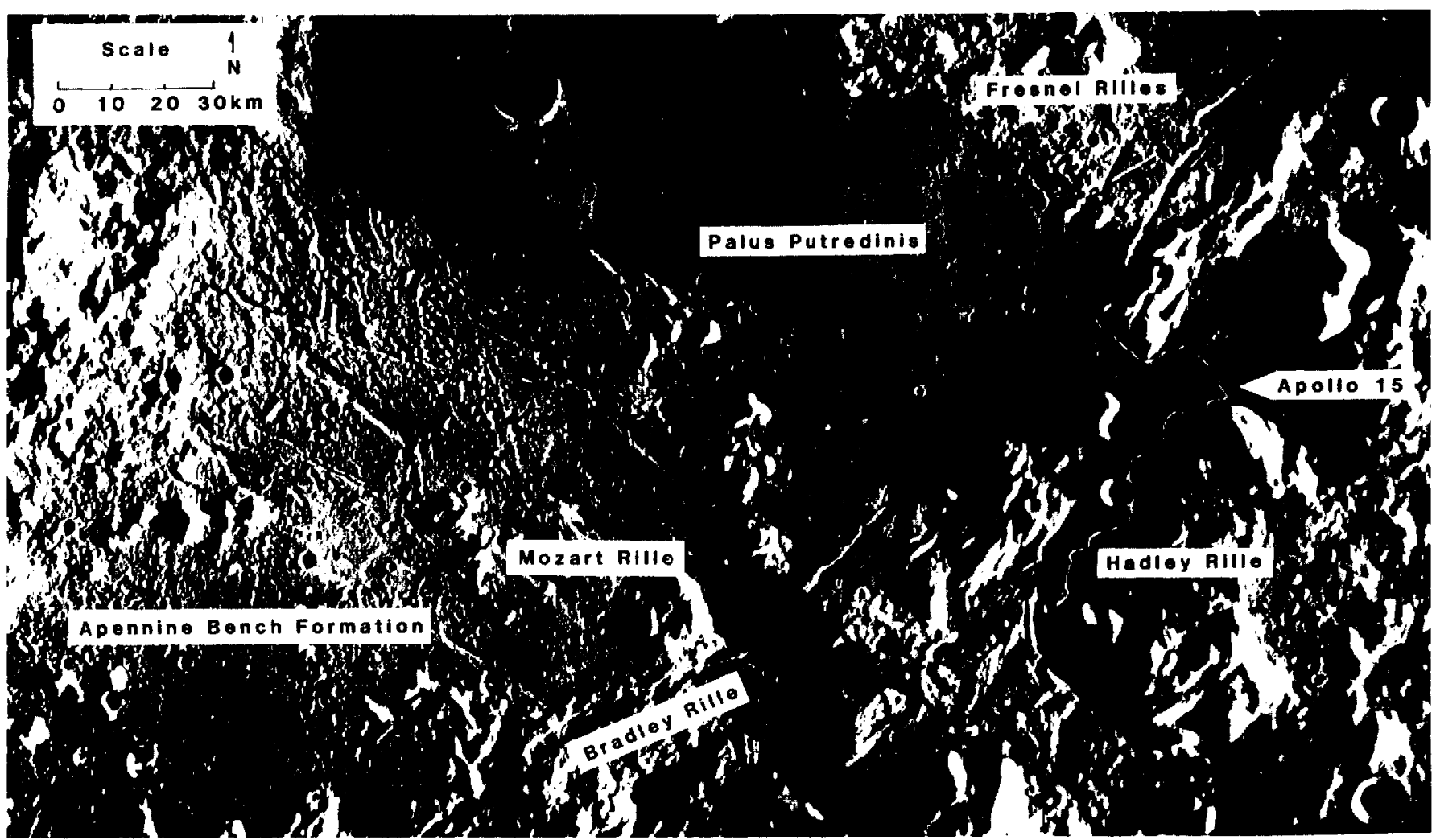

Figure 1. Orbital photograph of the Apollo 15 landing site and relevant environs. In addition to the large area to the left of the picture, the Apennine Bench Formation occurs at the area of the Fresnel Rilles. It probably also underlies the mare near the Apollo 15 landing site and may even be exposed at the North Complex (a dimple just to the north of the landing site) and elsewhere nearby. The mountains to the right are the Apennines, a prominent ring of Imbrium.

derlies mare basalts. Bench material may underlie mare basalts in the vicinity of the landing site, according to stratigraphic extrapolation and reconstruction. It may even have been exposed at the North Complex, intended to be visited on the Apollo 15 mission but missed because of a delay. Fragments of the Apennine Bench Formation are also likely to have been transported to the landing site by impacts, including the Archimedes-forming event. Numerous small fragments of KREEP basalt are indeed ubiquitous among the Apollo 15 samples, from both the mare plains and from the lower slopes of the massifs; they must represent a local, and not merely exotic, component. Radiogenic data show that these fragments have crystallization ages older than the local mare basalts, and most stratigraphic reconstructions of the landing site sandwich their parental unit between the mare basalts and the underlying Imbrium ejecta (Spudis, 1978; Hawke and Head, 1978). The chemistry of these fragments as derived from sample analysis is consistent with that inferred for the Apennine Bench Formation; they have a range of about $10-14 \mathrm{ppm}$ Th (e.g. Dymek, 1986, and Ryder, 1988, unpublished data and compilation). There is no simple alternative to the conclusion that the Apollo 15 KREEP basalts and the Apennine Bench Formation are one and the same.

\section{Apollo $15 \mathrm{KREEP}$ basalts are volcanic in origin and $3.84 \pm 0.02$ Ga old}

There has been considerable doubting that the Apollo 15 KREEP basalts are of volcanic rather than impact origin (e.g., Taylor, 1982), despite their lack of clastic inclusions (Fig. 2) and complete lack of meteoritic siderophile contamination. However, their volcanic origin can be demonstrated with some certainty. Although they form a coherent chemical group, analyses of fine-grained samples demonstrate that they have a variation showing a negative correlation between $\mathrm{MgO}$ and $\mathrm{Sm}$ (Fig. 3) and between $\mathrm{Cr}$ and $\mathrm{Sm}$, with a dominant range of $\mathrm{Mg} /(\mathrm{Mg}+\mathrm{Fe})$ of 0.64 to 0.55 as $\mathrm{Sm}$ ranges from 29 to 38 $\mathrm{ppm}$; the most primitive samples have $\mathrm{Mg} /(\mathrm{Mg}+\mathrm{Fe})$ of about 0.70 . The analyses lie along the plagioclase-pyroxene cotectic in the Si-Ol-An pseudoternary (Ryder. 1989, and in preparation). This is consistent with fractional crystallization and separation of about $30 \%$ plagioclase and low-Ca pyroxene (the 

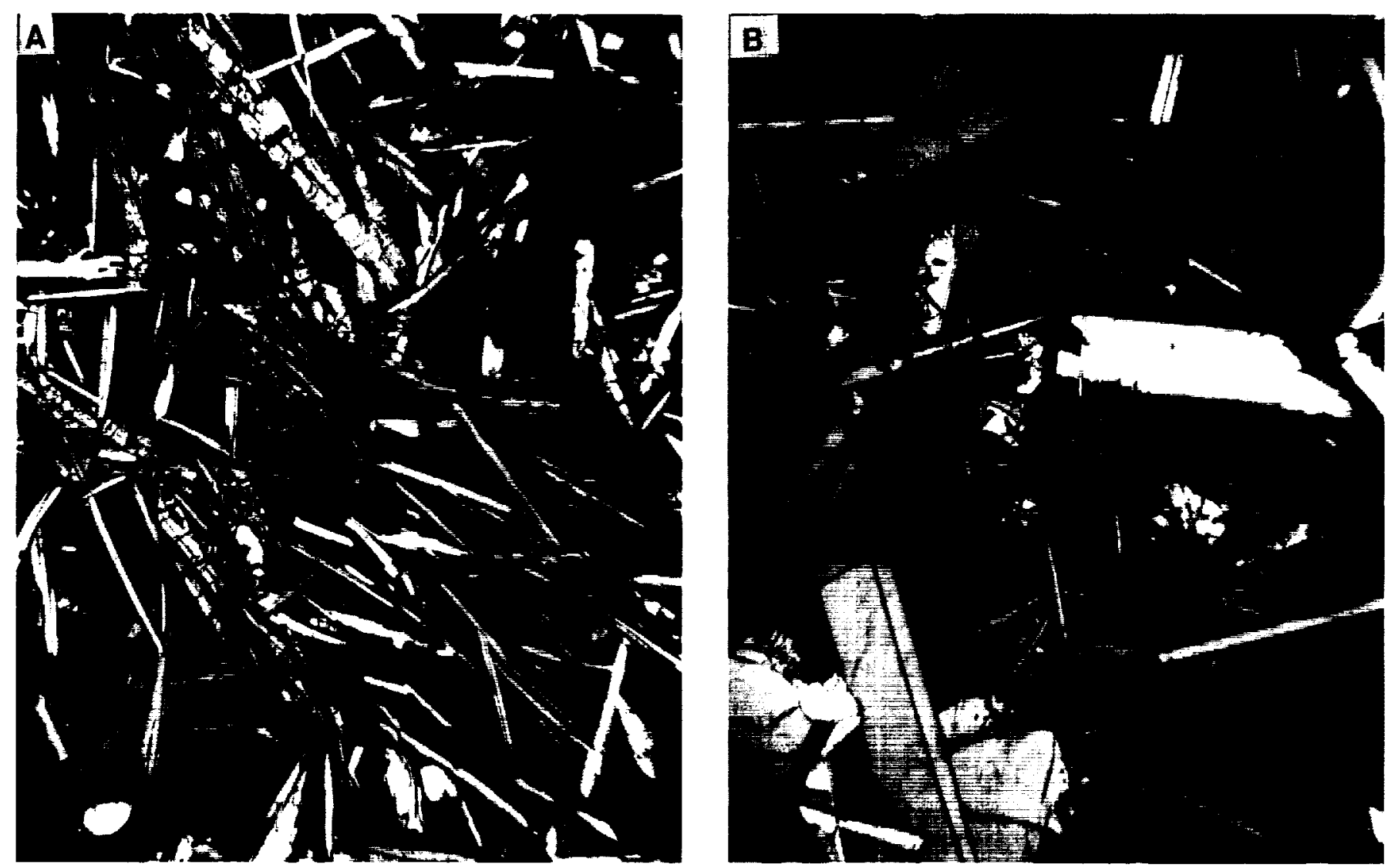

Figure 2. Crossed polarized photomicrographs of Apollo 15 KREEP basalt fragments; fields of

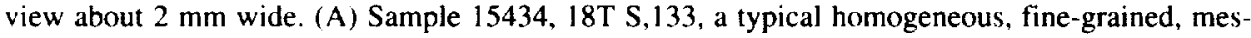
ostasis-rich basalt with pyroxenes partially surrounding needles of plagioclase. (B) Sample 15404,5T S.29 (on 15999,98), a glomeroporphyritic sample with plagioclase-orthopyroxene composites enclosed in a much finer-grained, mesostasis-rich groundmass.

\section{Chemistry of KREEP basalts}

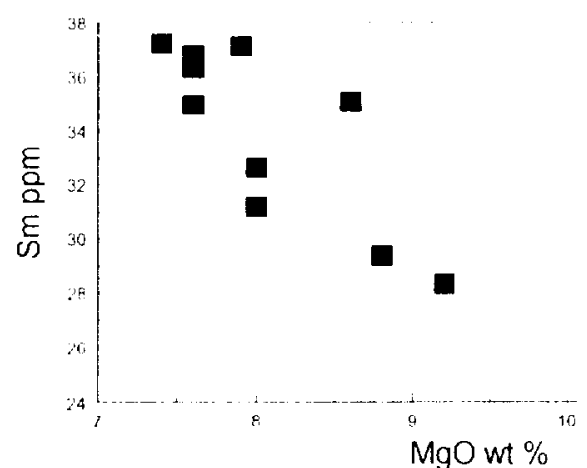

Figure 3. Sm ppm versus $\mathrm{MgO}$ wt $\%$ for fragments of Apollo 15 KREEP basalts. All data from particles analyzed by Ryder, and listed in Ryder and Sherman (1989). early crystallizing phases of the samples) and inconsistent with crystallization of fine-grained impact melt sheets. Furthermore, these variations do not result from sampling errors; the $\mathrm{Mg} /(\mathrm{Mg}+\mathrm{Fe})$ of the bulk samples correlates reasonably well with the $\mathrm{Mg} /(\mathrm{Mg}+\mathrm{Fe})$ of the most magnesian orthopyroxenes in the samples (Fig. 4) (Ryder, 1989). The parental melts were all related and underwent fractional crystallization before flowing to their final solidification locale.

The textural characteristics of the KREEP basalts indicate that some of them had two-stage cooling histories, also much more consistent with a volcanic origin (Ryder, 1987), insofar as they suggest a dynamic and varied crystallization environment. Such evidence includes orthopyroxene phenocrysts alone in a multi-saturated magma, glomerocrysts of orthopyroxene and plagioclase (Fig. $2 b$ ), and quenched clear glass mesostases in coarse-grained fragments. Such features cannot be expected in the fairly static environment of the crystallization of an impact melt. There is a great difference in the environment of a melt that is not being continuously produced and that of a melt that is being continuously fed from extrusion. 


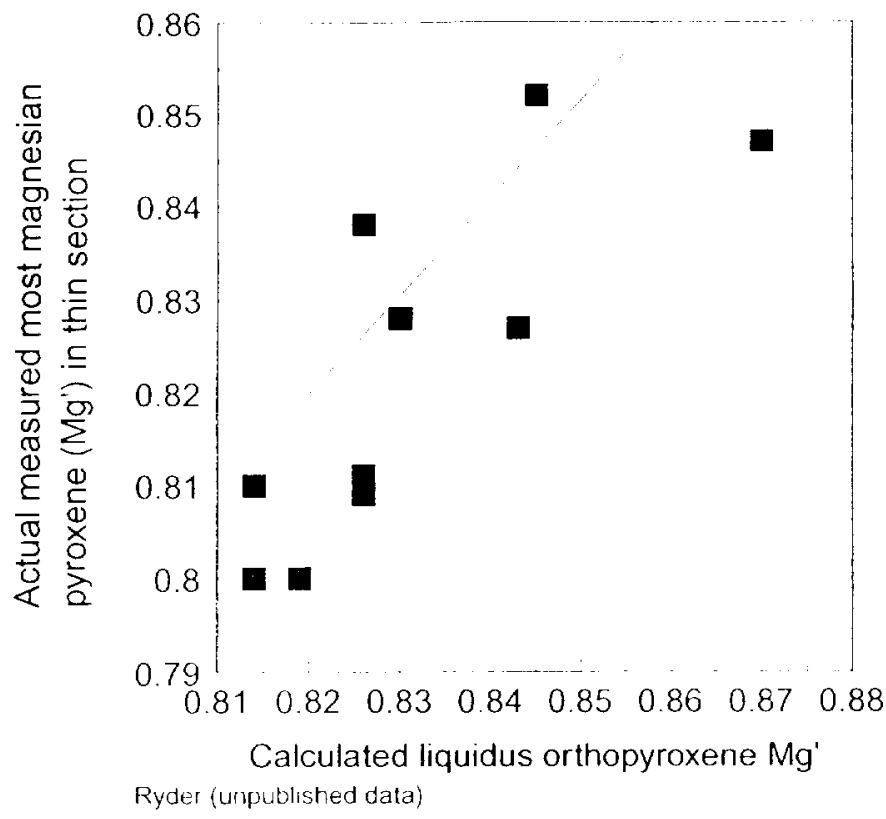

Figure 4. Comparison of most magnesian low-Ca pyroxene cores, expressed as their $\mathrm{Mg} /(\mathrm{Mg}+\mathrm{Fe})$, in the Apollo $15 \mathrm{KREEP}$ samples with the corresponding liquidus low-Ca pyroxene composition, calculated from the bulk sample using a distribution coefficient, $(\mathrm{Mg} / \mathrm{Fe}$ liquid)/(Mg/Fe crystal), of 0.28 . All data is from G. Ryder (1988, unpublished. Samples are the subset of those in Figure 3 for which mineral chemical analyses were made.

If they were from an impact melt sheet, the Apollo 15 KREEP basalts would be expected to have reasonably typical crustal compositions; instead they are quite distinct from acceptable typical crustal composites. Indeed, they are far too rich in incompatible element abundances ( $150 \times$ chondrites) to represent much of a typical crustal column. Even if all such elements were in the crust, heat flow and other considerations permit a maximum overall crustal abundance of incompatible elements of about $20 \times$ chondritic abundances. The Apennine mountains, reasonably representing regional crustal compositions and presumably including material ejected from the basin, contain much lower abundances of radioactive incompatible elements, such as Th, than does the Apennine Bench (Metzger et al., 1979). So do some impact melt samples collected at the Apollo 15 site reasonably inferred to be Imbrium impact melt (Ryder and Bower, 1977). Furthermore, a crustal column tens of kilometers deep of the composition of Apollo 15 KREEP basalts would probably have melted from its own internal heat generation well before the Imbrium basin formed.

The Serenitatis impact melt, as believed to have been sampled on the Apollo 17 mission, consists of fine-grained, generally poikilitic, clast-bearing and meteorite-contaminated rocks with a uniform composition (Spudis and Ryder, 1981). There is no evidence for the possibility (because of their fine grain size) or actuality (from their chemical homogeneity) that their parent melt fractionated by crystal separation. No equivalents of the Apollo 15 KREEP basalts that might be connected with the Serenitatis basin as coarse, siderophile-free, clast-free impact melts have been discovered, and suggest that coarse volcanic-like, differentiated melt sheets do not exist, at least so far from a basin center (the Apollo 15 and Apollo 17 sites are in at least roughly analogous positions relative to their basins). The inferred Serenitatis impact melt contains only about $60 \times$ chondritic abundances of incompatible elements, allowing it to more reasonably represent a significant crustal proportion than do the Apollo 15 KREEP basalts.

It has been suggested that the Sudbury Complex might represent a differentiated melt sheet (Grieve et al., 1991), thus in turn making a case for the possibility of lunar basin melt differentiation. However, the Sudbury case is described as a working hypothesis (Grieve et al., 1991) and is far from proven. If the Apollo 15 KREEP basalts were differentiated from a large crustal impact melt, then the extent of differentiation was of the order of at least 60 or $70 \%$ prior to the release of the KREEP basalts so far collected, and the initial melt (hence crust) would then have had a high $\mathrm{Mg} /(\mathrm{Mg}+\mathrm{Fe})$ ratio, at least approaching 0.90 and unlike accepted crustal averages. Such a starting melt composition would have been quite unlike the Serenitatis impact melt. All samples of the Apollo 15 KREEP basalts are quite fine grained, and samples of any related cumulate pile have not been recognized. It has not been shown that clast-free, volcanic-like basalts were extruded during the differentiation of the Sudbury Complex; all superficial units are clast rich.

Unlike terrestrial impact melts, for which the siderophiles must come from the impactor, lunar impact melts are unlikely to avoid the siderophiles that are present in at least the upper part of the target, and the Apollo 15 KREEP basalts completely lack meteoritic contamination.

Radiogenic isotopic data for three fragments of Apollo 15 KREEP basalt fragments by three different techniques show consistent crystallization ages when calculated using the decay constant values recommended by Steiger and Jäger (1977) (Fig, 5). (All ages quoted in this paper have uncertainties of \pm 2 sigma as stated in the sources). Assuming that all three fragments date the same geologically instantaneous volcanic event, this took place at $3.84 \pm 0.02 \mathrm{Ga}$. However, one of the fragments is distinct in its initial $\mathrm{Sr}$ isotopic ratio. Although this can be taken to indicate a separate flow, the chemistry and petrography of the sample make it otherwise indistinguishable from other Apollo 15 KREEP basalts. It is entirely possible by terrestrial comparison that assimilation has affected initial $\mathrm{Sr}$ isotopic ratios in these basalts or that a series of related flows have slightly different ratios.

\section{The Imbrium event took place $3.84 \pm 0.02 \mathrm{Ga}$}

The Apennine Bench Formation/Apollo 15 KREEP basalts provide a lower limit to the age of Imbrium of $3.84 \pm 0.2$ $\mathrm{Ga}$. A rough upper limit can be established by the age of 


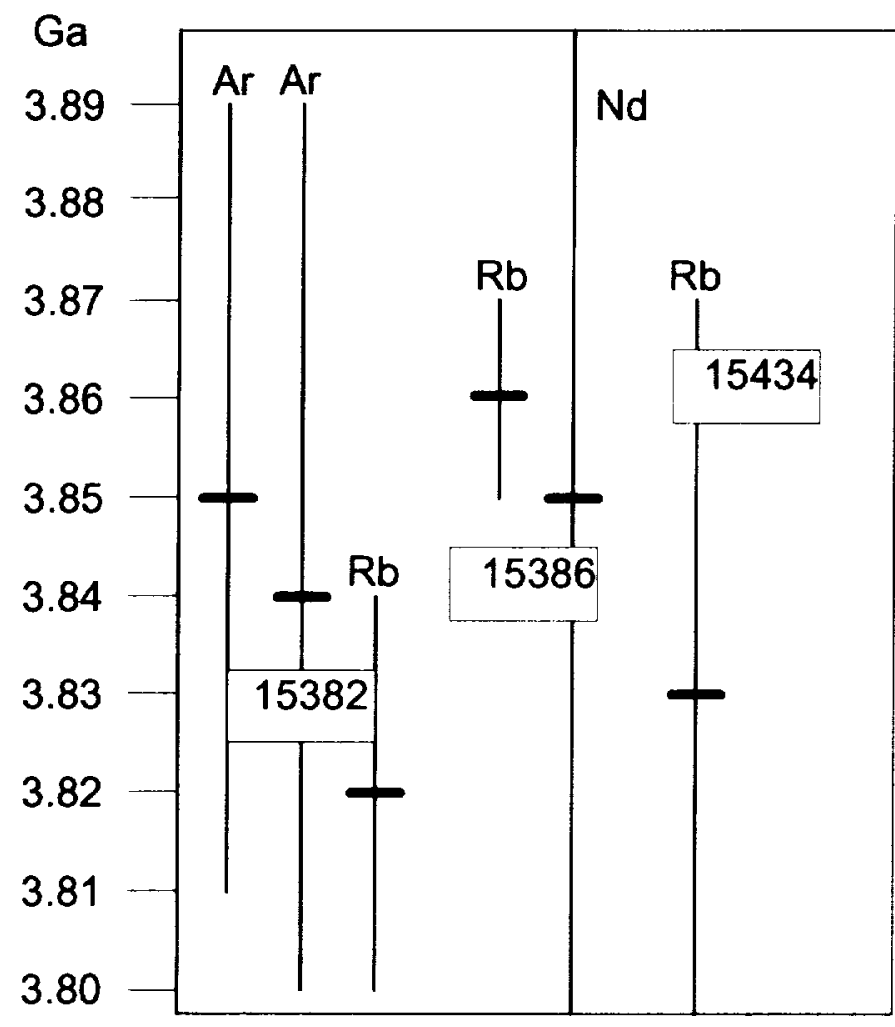

Figure 5. Ages of Apollo 15 KREEP basalt samples 15382, 15386, and 15434,16 from published sources (for references see Ryder, 1985; Ryder and Sherman, 1989; and Shih et al., 1992). Isotopic systems used are indicated. Error bars are the 2-sigma uncertainties quoted in the sources.

Serenitatis, whose melts have been identified and dated as close to $3.87 \mathrm{Ga}$ (summarized in Wilhelms, 1987). The best way to date the Imbrium event would be to date its impact melt directly, as is believed to have been achieved for Serenitatis. Unfortunately, it cannot be positively established which, if any, of the available samples represent an Imbrium melt. However, geological analysis of the Apennine Front shows that virtually all the highlands samples collected from there must be either the same age as Imbrium or be older than it; this is especially true of crystalline impact melts, as no major regional impact events postdate Imbrium. Thus the youngest of crystalline impact melt samples from the Apennine Front should provide a reasonable upper limit for the age of Imbrium.

Few definitive age data have been available for Apollo 15 impact melt samples until recently. Most are fine grained and not amenable to $\mathrm{Rb}-\mathrm{Sr}$ or $\mathrm{Sm}-\mathrm{Nd}$ dating. Disturbance and small clasts have influenced Ar dating. Dalrymple and Ryder (1991, 1993) have dated Apollo 15 impact melt samples of varied chemical composition using ${ }^{40} \mathrm{Ar}-{ }^{39} \mathrm{Ar}$ laser incremental heating techniques that avoid some of the problems. While four mainly glassy samples show later disturbances precluding definitive ages, eight provide interpretable plateaus. Seven define melt ages in the range from 3.852 to $3.870 \mathrm{Ga}( \pm 0.015)$, while an eighth poikilitic sample gives an age of $3.836 \pm 0.011$ $\mathrm{Ga}$. These data strongly suggest an age for Imbrium of $3.84 \pm$ $0.02 \mathrm{Ga}$ (placing the uncertainty conservatively) if it is accepted that most of the melts must predate Imbrium (i.e., they are part of the ejecta pile). The ages of the older samples are the same as those of Serenitatis. While other younger ages for Imbrium have been suggested on the basis of Apollo 14 samples (Deutsch and Stoffler, 1987; Stadermann et al., 1991), they are completely inconsistent with the lower limit placed by the age of the Apennine Bench Formation/Apollo 15 KREEP basalts; with such a young Imbrium age, the Apennine Bench has to be assumed to be a pre-Imbrium block downfaulted without great disruption during the formation of the basin. Furthermore, the Apollo 14 samples dated as young are not from Cone Crater ejecta and cannot be demonstrated to be a part of the Fra Mauro Formation. They were probably merely ejected onto it by later, local events.

\section{The KREEP volcanism of the Apennine Bench Formation was unique}

Analysis of regional geology and of the Apollo 15 and Apollo 14 samples demonstrate that any KREEP volcanism that occurred in the eastern part of the Imbrium basin after the emplacement of the Apennine Bench Formation must have been minor. None are visible with current methods of resolution, although there is at least sample evidence for some mare basalts somewhat elevated in incompatible elements (but not KREEP-like) in lower Imbrian times. Thus the KREEP volcanism in the region immediately followed the Imbrium event and then terminated completely.

The Apollo 15 landing site contains abundant small fragments of the Apollo 15 KREEP basalt, but as far as can be inferred, they all belong to one and the same series or related series of fractionated flows. If any of these are older than Imbrium, they are not petrographically distinct and have not been dated. Abundant petrographic and chemical work has been done on these samples, so this similarity is not in doubt. The only other KREEP volcanic type so far found at the Apollo 17 site is quite distinct and would have been recognized as such within the Apollo 15 samples. Clearly more chronological work needs to be done on Apollo 15 KREEP basalts, but the present inference, given the variety of older igneous anorthosites, norites, and troctolites, and metamorphic granulites that have been obtained, must be that older KREEP volcanics were barely present in the pre-Imbrium target or the pre-Apennine Front region. If the target had included a terrain similar to the Apennine Bench but with a somewhat different type of KREEP basalt, it would probably have recognizably contributed to the sample collection. However, the absence of pre-Imbrium KREEP volcanism is far less certain than the absence of post-Imbrium KREEP volcanism, especially as no 
older volcanics of any kind have been identified in the Apollo 15 collection.

The present evidence suggests, although certainly does not prove, that the Apennine Bench Formation/Apollo 15 KREEP volcanics are unique in regional history: a similar extensive extrusion had probably not happened there for some extended time before, and it certainly did not happen again.

\section{The coincidence in time of Imbrium and the unique Apennine Bench Formation requires a genetic relationship}

The inferred absolute ages of the Imbrium event and the Apennine Bench Formation combined with their relative stratigraphy are most consistent with the Imbrium event only marginally preceding the massive volcanic extrusion. The radiogenic data indeed cannot distinguish the events at all. Although the stated (roughly 2 sigma) uncertainties allow a maximum age of Imbrium of 3.86 (or 3.85 ) Ga and a minimum age of KREEP volcanism of $3.82 \mathrm{Ga}$, and thus a difference of $40 \mathrm{Ma}$, this is a most unlikely underlying reality for such measured age distributions. It is far more likely, especially given that the Apennine Bench Formation cannot be older than Imbrium, that the distributions reflect an age difference of about $10 \mathrm{Ma}$ or less. Even if it is as much as $20 \mathrm{Ma}$, this is less than $0.5 \%$ of lunar history, and is almost a coincidence in time. It is difficult to avoid the conclusion of some kind of cause and effect, i.e., that the Imbrium basin formation induced the flooding of part of the basin with KREEP lavas. The impact may have actually induced the melting or have facilitated the release of existing melts that otherwise would not have been extruded.

\section{THE NATURE OF IMPACT-INDUCED VOLCANISM FOR THE APENNINE BENCH FORMATION}

Inducement of partial melting can conceivably take place by the decompression of the sub-target area following the impact or by heat input from the impact, or both. Both heat and pressure effects would be greatest at the very center of the basin. However, the heat input even for a basin-producing impactor is of very shallow extent (i.e., does not extend greatly below the basin or crater floor) and is mainly taken up by the production of impact melt, and on the Moon the pressure release is rather small. Because of the small gravity field on the Moon, the pressure relief of unloading even $100 \mathrm{~km}$ is only $0.5 \mathrm{GPa}$, and brings a mass of suitable rock only $60^{\circ} \mathrm{K}$ closer to its melting point (e.g., Melosh, 1989). The unloading of the lunar lower crust at less than $60 \mathrm{~km}$ would have been less than that, and with latent heat of melting to take into account, not much melting can be expected. Thus, if impact-induced crustal melting is responsible for the Apollo 15 KREEP basalts, the source must have been at or very close to its melting temperature anyway, or other melts induced by pressure release of the mantle added their heat to the source of the KREEP basalts by upward movement without either mixing with that source or actually reaching the surface themselves.
The chemical and isotopic evidence suggest that a large amount of partial melting of a crustal source (or mantle source contaminated with crustal materials) is required to produce the Apollo 15 KREEP basalts. The inferred source retained magnesian low-Ca pyroxene but not calcic pyroxene (e.g.. Irving, 1977), suggestive of a large degree of melting for a crustal source. The typical KREEP rare earth element pattern and isotopic characters of the basalts suggest that their melting at 3.84 Ga retained the source trace element characteristics set at 4.3 or $4.4 \mathrm{Ga}$; such retention is incompatible with small degrees of partial melting, particularly of an orthopyroxene + plagioclase source (Ryder, 1987 and references therein). These constraints suggest degrees of partial melting of at least $30 \%$. The most primitive KREEP basalts also have $\mathrm{Mg} /(\mathrm{Mg}+\mathrm{Fe})$ of about 0.70 , inconsistent with small amounts of partial melting other than from a very magnesian source. Large amounts of partial melting are almost impossible to accommodate with thermal constraints of impact-induced melting alone of even hot crust. The Imbrium impact instead may have served to release magma that already existed in a hot lower crust but that was too viscous or too deep or too dense to have self-released. If there was already igneous melt below the target, then the removal of crust by the impact or the creation of conduits by fracturing could easily have triggered volcanism. Such a melt might have existed previously for considerable periods of time if it was generated by internally produced radiogenic heat and does not require any particular coincidence in being present at the time of the Imbrium impact. Insofar as the Imbrium basin is not only the largest prominent front-side basin but is also in a terrain generally richer in KREEP than regions such as the Orientale target, impact-induced or -released melting might have been unique to the Imbrium event.

\section{IMPACT-INDUCED VOLCANISM ON THE EARTH}

If volcanism was induced even once on the Moon, a small body, at about $3.84 \mathrm{Ga}$, then it becomes more acceptable that it was induced on larger, hotter bodies at the same time or earlier if they were subject to a similar population of impactors.

The oldest terrestrial rocks of any significant volume have an age similar to that of the lunar cataclysmic bombardment. Older terrestrial crust either did not exist, was essentially annihilated at that time, or has since been obliterated. A hotter earth at $3.84 \mathrm{Ga}$ was perhaps very susceptible to impactinduced partial melting, causing very extensive recycling even of otherwise non-subductable granitic crust. Planetesimals hitting the Earth at that time would have been traveling faster than those that hit the Moon, and many of them would have been larger (because the Earth's much larger cross-section would have sampled a much larger total number of the same population). The effects of pressure release would have been greater than on the Moon because of the stronger gravity field, the deeper penetration of the larger projectiles, and the presence of more sub-target material close to or above its melting 
temperature. Such melting could have had drastic effects in remixing and assimilating old crust into upper mantle material to add to an assumed plate-tectonic recycling that could not by itself have been very efficient for granitic material and for establishing tectonic regimes that would not have existed with only endogenous influences. Thus impact-induced volcanism may be responsible for the annihilation of the most ancient terrestrial crust. Following the termination of heavy bombardment at about $3.83 \mathrm{Ga}$, such inducement may have become either rare or absent.

\section{ACKNOWLEDGMENTS}

Reviews of the manuscript by W. B. McKinn, J. S. Alexopoulos, A. Basu, and P. D. Spudis contributed to improvement of the presentation of the ideas expressed in this paper. The work was done with support from the NASA Planetary Materials and Geochemistry Program. This paper is LPI Contribution 812. The Lunar and Planetary Institute is operated by the Universities Space Research Association under contract NASW-4066 with the National Aeronautics and Space Administration.

\section{REFERENCES CITED}

Adler, I., and Trombka, J. I., 1977, Orbital geochemistry-lunar surface analysis from the $\mathrm{X}$-ray and gamma-ray remote sensing experiments: Physics and Chemistry of the Earth, v. 10, p. 17-43.

Dalrymple, G. B., and Ryder, G., 1991, ${ }^{40} \mathrm{Ar} /{ }^{39} \mathrm{Ar}$ ages of six Apollo $15 \mathrm{im}$ pact melt rocks by laser step heating: Geophysical Research Letters, v. 18 , p. 1163-1166.

Dalrymple, G. B., and Ryder, G., 1993, ${ }^{40} \mathrm{Ar} /{ }^{34} \mathrm{Ar}$ age spectra of Apollo 15 impact melt rocks by laser step-heating: Journal of Geophysical Research, v. 98, p. 13085-13095.

Deutsch, A., and Stoffler, D., 1987, Rb-Sr analyses of Apollo 16 melt rocks and a new age estimate for the Imbrium basin; Lunar basin chronology and the early heavy bombardment of the Moon: Geochimica et Cosmochimica Acta, v. 51, p. 1951-1964.

Dymek, R. F., 1986, Characterization of the Apollo 15 feldspathic basalt suite [abs.l, in Workshop on the geology and petrology of the Apollo 15 Landing Site, Spudis, P. D., and Ryder. G., eds.: Lunar and Planetary Institute Technical Report 86-03, p. 52-57.

Grieve, R.A.F., Stoffler, D., and Deutsch, A., 1991, The Sudbury structure; Controversial or misunderstood?: Journal of Geophysical Research, v. 96, p. $22,753-22,764$.

Hackman, R. J., 1966, Geologic map of the Montes Apenninus quadrangle of the Moon: U.S. Geological Survey Map I-463 (LAC-41), scale 1:1,000,000.

Hawke, B. R., and Head, J. W., 1978, Lunar KREEP volcanism: Geologic evidence for history and mode of emplacement: Proceedings, Lunar and
Planetary Science Conference, v. 9, p. 3285-3309.

Howard, K. A., and Wilshire, H. G., 1975, Flows of impact melt at lunar craters: U.S. Geological Survey Journal of Research, v. 3, p. 237-257.

Irving, A. J., 1977, Chemical variation and fractionation of KREEP basalt magmas: Proceedings, Lunar Science Conference, v. 8, p. 2433-2448.

Melosh, H. J., 1989, Impact cratering: New York, Oxford University Press, $245 \mathrm{p}$.

Metzger, A. E., Haines, E. L., Etchegaray-Ramirez, M. I., and Hawke, B. R., 1979. Thorium concentrations in the lunar surface; III. Deconvolutions of the Apenninus region: Proceedings, Lunar and Planetary Science Conference, v. 10, p. 1701-1718.

Page, N. J., 1970, Geologic map of the Cassini quadrangle of the Moon: U.S. Geological Survey Map I-666 (LAC-25), scale 1: 1,000,000

Ryder, G., 1985, Catalog of Apollo 15 rocks: Johnson Space Center, JSC 20787, Curatorial Branch Publication 72, 1295 p.

Ryder, G., 1987, Petrographic evidence for nonlinear cooling rates and a volcanic origin for Apollo 15 KREEP basalts: Proceedings, Lunar and Planetary Science Conference, v. 17, p. E331-E339.

Ryder, G., 1989, Petrogenesis of Apollo 15 KREEP basalts [abs.], in Lunar and Planetary Science Conference, 20th: Houston, Lunar and Planetary Science Institute, v. 20, p. 936-937.

Ryder, G., and Bower, J. F., 1977, Petrology of Apollo 15 black-and-white rocks 15445 and 15455-Fragments of the Imbrium impact melt sheet?: Proceedings, Lunar Science Conference, v. 8, p. 1895-1923.

Ryder, G., and Sherman, S. B., 1989, The Apollo 15 coarse fines (4-10 mm): Johnson Space Center, JSC 24035, SSED [Solar System Exploration Division] Planetary Science Branch Publication 81, 207 p.

Shih, C.-Y., Nyquist, L. E., Bansal, B. M., and Weismann, H., 1992, Rb-Sr and Sm-Nd chronology of an Apollo 17 KREEP basalt: Earth and Planetary Science Letters, v. 108, p. 203-215.

Spudis, P. D., 1978, Composition and origin of the Apennine Bench Formation: Proceedings, Lunar and Planetary Science Conference, v. 9, p. $3379-3394$.

Spudis, P. D., and Ryder, G., 1981, Apollo 17 impact melts and their relation to the Serenitatis basin: Multi-ring basins: Proceedings, Lunar and Planetary Science Conference, v. 12A, p. 133-148.

Spudis, P. D., Hawke, B. R., and Lucey, P. G., 1988, Materials and formation of the Imbrium Basin: Proceedings, Lunar and Planetary Science Conference, v. 18 , p. 155-168.

Stadermann, F. J., Heusser, E., Jessberger, E. K., Lingner, S., and Stoffler, D., 1991. The case for a younger Imbrium basin: New ${ }^{40} \mathrm{Ar}-{ }^{39} \mathrm{Ar}$ ages of Apollo 14 rocks: Geochimica et Cosmochimica Acta, v. 55, p. $2339-2349$.

Steiger, R. H., and Jäger, E., 1977, Subcommission on geochronology: Convention on the use of decay constants in geo- and cosmochronology: Earth and Planetary Science Letters, v. 36, p. 359-362.

Taylor, S. R., 1982, Planetary Science: A lunar perspective: Houston, Lunar and Planetary Institute, $481 \mathrm{p}$.

Wilhelms, D. E., 1970, Summary of lunar stratigraphy-telescopic observations: U.S. Geological Survey Professional Paper 599-F, 47 p.

Wilhelms, D. E., 1987. The geologic history of the Moon: U.S. Geological Survey Professional Paper 1348, 302 p.

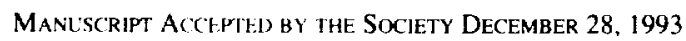

